\title{
Novel approach on Formamidinium tin iodide-based Perovskite solar cell for the best replacement materials of Hole Transport Layer and Electron Transport Layer by using Solar cell Capacitance simulation
}

\section{Vishnuwaran}

SRMIST: SRM Institute of Science and Technology

Krishnamoorthy Ramachandran ( $\nabla$ kaviramach76@gmail.com )

SRMIST: SRM Institute of Science and Technology https://orcid.org/0000-0002-0977-186X

\section{Research Article}

Keywords: Lead-free, Perovskite solar cell, SCAPS-1D Simulation, Zinc oxysulphide (ZnOS), Copper iodide (Cul), Electron transport layer (ETL), Hole transport layer (HTL)

Posted Date: January 31st, 2022

DOI: https://doi.org/10.21203/rs.3.rs-1265526/v1

License: (1) This work is licensed under a Creative Commons Attribution 4.0 International License. Read Full License 


\section{Abstract}

Perovskite Solar Cells (PSC) research has increased noticeably in recent years as a result of significant improvements in their performance. Perovskite solar cells are a new development in Photovoltaic technology. Because PSCs are inexpensive, have the ability to tune the bandgap and are a promising future option for meeting cell efficiency limits and strong broad optical absorption. Toxicity is an important factor in the development of organic and inorganic Perovskite solar cells. PSCs based on Sn are a worthy competitor to PSCs based on Lead $(\mathrm{Pb})$. The majority of them used Methylammonium tin iodide $\left(\mathrm{CH}_{3} \mathrm{NH}_{3} \mathrm{Snl}_{3}\right)$ material as an absorber layer because it has greater absorption but suffers from temperature instability. As a result, in this work, we use Formamidinium tin iodide ( $\mathrm{FASnl}_{3}$ ) absorber, which has higher temperature stability than $\mathrm{CH}_{3} \mathrm{NH}_{3} \mathrm{Snl}_{3}$ Methylammonium tin iodide with a band gap of $1.4 \mathrm{eV}$. Solar cell Capacitance simulation used in this work to create $\mathrm{FASnI}_{3}$-based solar cells. This paper proposes a Power Conversion Efficiency of $24.22 \%$ for PSCs. For maximum Power Conversion Efficiency (PCE), the optimized thickness values are $10 \mathrm{~nm}$ for Cul (Hole transport layer), $850 \mathrm{~nm}$ for $\mathrm{FASnl}_{3}$, and 20 $\mathrm{nm}$ for ZnOS (Electron Transport Layer). The best temperature range for device performance is around $340 \mathrm{~K}$. SCAPS was used to calculate the current work. In addition, we demonstrated that ZnOS is the most promising $\mathrm{ETL}$ as a $\mathrm{TiO}_{2}$ replacement in this work. The proposed work focuses on paving the way for novel eco-friendly non-toxic PSCs as well as investigating optimised Voltage output circuit (Voc), Current density (Jsc), Fill factor (FF), and Power conversion Efficiency (PCE) device characteristics.

\section{Introduction}

Nowadays Perovskite solar cell is the mainstream in PV technology with high PCE and PSCs is the best competitor for Si-wafer based solar cells [1]. Recently in perovskite solar cell, halides-based PSCs has the most promising absorber materials in PSCs [2]. The power conversion efficiency of PSCs which is based upon $\mathrm{Pb}-\mathrm{PSC}$ had a dramatic improvement from $3.08 \%$ to recently certify the value of $25.5 \%$ [3]. However, there are some shortcomings faced on Pb based PSCs. Like toxicity, thermal stability, air stability and non-ecofriendly to the humans. These are some of the disadvantages for Pb-based PSCs [4]. For that reasons pollution free and safety to humans, it is emergently needed to develop a nontoxic or low toxic metal to replace the $\mathrm{Pb}$ based ab-layer of PSCs. Therefore, research had to be made to replace $\mathrm{Pb}$ with some low and nontoxic materials in $\mathrm{PSC}_{\mathrm{S}}$ [5]. $\mathrm{Sn}, \mathrm{Cu}, \mathrm{Bi}$, and $\mathrm{Sb}$ have all been studied as potential replacements for $\mathrm{Pb}$-PSCs [6]. Sn has emerged as the most promising immediate replacement material for $\mathrm{Pb}$-based PSCs among these. Because $\mathrm{Sn}$ belongs to the same group as $\mathrm{Pb}$ in the periodic table, its electric and optical properties are too similar, making $S n$ the best replacement material in PSCs [7].

The general formula for organic and inorganic halide perovskite solar cells is $A B X_{3}$, where $A$ and $B$ are cations and $X$ is always a halogen. MA, FA, and $C$ s are the most commonly used cations (A) in PSC [8]. From 4th and 7th, group elements are widely used as a $B$ cation and $X$ halogen respectively [9]. In this work, we use $\mathrm{Sn}$ be the replacement of $\mathrm{Pb}$. $\mathrm{Sn}$ is not only for the alternative ion to $\mathrm{Pb}$, it is also to enhance ecofriendly of PSCs [10]. Due to temperature instability in $\mathrm{CsSnl}_{3}$ and $\mathrm{MASnl}_{3}$ we use the $\mathrm{FASnl}_{3}$ as the 
Ab-layer in this simulated work [11]. FASnl 3 had a more solid perovskite structure, more stable and also the air stability is high compared with $\mathrm{MASnl}_{3}$. These are the reasons we use $\mathrm{FASnl}_{3}$ having a perovskite layer for this simulated Device. Recently many approaches have been done to improve the $\mathrm{FASnl}_{3}$ based device [12]. $\mathrm{FASnl}_{3}$ has higher carrier mobility than $\mathrm{MASnl}_{3}$ according to Milot et al [13]. Krishna moorthy groups published the first study on FASnI 3 -based PSCs in 2015, with an efficiency of 1.41 percent [14]. $\mathrm{FASnl}_{3}$ with $\mathrm{Eg}(1.4 \mathrm{eV})$ which is wider than $\mathrm{MASnl}_{3}$ and $\mathrm{CsSnl}_{3}(1.30 \mathrm{eV})$ respectively and narrow to $\mathrm{Pb}$ based PSCs. Also, in FASnX 3 can be tuned the Eg with different halides [15]. Recently Cul had attained PCE $17.6 \%$ which is based upon spray deposition method [16]. Cul had a high electric conductivity compared with Spiro-MeOTD. For that reason, we use Cul as a HTM in this work. Cul [17]. Bansal had investigated $\mathrm{MASnl}_{3}$ based solar cell with different ETL and HTL they achieved the PCE $21.1 \%$ in that ZnOS act as ETL [18]. Currently, before fabricating a cell or a device, the theoretical studies help more to understand and find the behavior of the cell Devices [19]. In recent days, many simulation devices are studied for PSCs with novel materials in SCAPS (1D) [20]. The initial structure is based on an $11.01 \%$ working PCE. After several optimizations on the thickness of the ab-layer, HTL and ETL, the simulated devices achieve an efficiency of $24.22 \%$. At this present work, we optimized Novel FASnl ${ }_{3}$ based Perovskite solar cell with Cul and ZnOS act as a very promising HTL and ETL respectively. Replacement of Spiro-MeOTD and $\mathrm{TiO}_{2}$ and also $\mathrm{FASnl}_{3}$ material is the best replacement for $\mathrm{MASnl}_{3}$ based solar cell.

\section{Methodology And Device Simulation 2.1. Basic Structure of the Device}

The device's simulated configuration is FTO / ZnOS / FASnl3 / Cul / Au. To date, three types of PSCs have been investigated: mesoporous planar, and inverted planar. The inverted planner configuration has been completed in this work and is shown in Fig. 1. (a) Device configurations of simulated PSCs, Cul as HTL and ZnOS as ETL. Energy band diagram for this device also shown in Fig (b). In Fig. 1(c, d) shown the initial Jsc, Voc, and \%PCE- wavelength studies. All the basic parameters are collected from various research papers and tabulated in Table. $1[3,10,15,21$, and 22]. Meng and his group report that at low temperature the inverted planar would exceed over $18 \%$ of efficiency flexibility with J-V hysteresis [23]. Table.2. Summaries the $N_{t}, N_{D}, N_{A}$, for the configuration of the device and the work function of front and back contact as FTO $(4 \mathrm{eV})$ and $\mathrm{Au}(5.1 \mathrm{eV})$ respectively $[24,25]$.

\subsection{Methodology of Simulation}

The simulated was performed in SCAPS 1D under AM 1.5G illumination. This simulation carries only inside the SCAPS-1D and mainstream to derive from the following fundamental equations Poisson, hole and electron continuity. All the simulated results were examined in separate sections through graphs for each stage. In initial structure results, values of is PCE $11.01 \%$, after several optimization on the absorber layer, HTL, ETL, and temperature in this device we constructed a novel PSCs with high efficiency. 


\section{Results And Discussions}

\subsection{Optimization and Simulation of FASnl 3 PSC}

\subsubsection{Effect of Temperature}

The temperature of the solar cell has an effect on its overall performance. In this simulation, we kept the temperature constant at $300 \mathrm{~K}$ at first and then varied it from $300 \mathrm{~K}$ to $400 \mathrm{~K}$ to determine the effect of working temperature on PCE, Voc, Jsc, and FF for the best ab-layer thickness, as shown in fig. In this simulated device, it was discovered that as the temperature increased, the PCE, Voc, Jsc, and FF of the solar cell decreased, because of carrier concentrations, charge carrier mobility and the material's bandgap at high temperatures (mariSoucase, et.al.2016). The efficiency slightly decreased from $24.09-23.64 \%$ at (300-400) K. The diffusion length reduces and series resistance increases. The resultant is decreased in PCE and FF (Mandadapu and group at 2017), because of the increase in energy enhanced recombination, electrons become unstable at higher temperatures in a solar cell, resulting in a low PCE (Mandadapu 2017). For that $340 \mathrm{k}$ is the working temperature for this simulation work.

\subsubsection{The Effect of the Ab-layer Thickness}

The ab-layer in PSCs absorbs photons from sunlight whose energy is greater than the bandgap of the ablayer, which causes excisions. These preciseions are essentially charged electron-hole pairs. To maximize PCE, it is necessary to understand the impact of defect density on PSC performance. Because the Ablayer is a critical factor in determining the performance of PSCs, its effect on solar cell output parameters has been studied using simulation. The active layer thickness was increased from $100 \mathrm{~nm}$ to $1050 \mathrm{~nm}$ in $850 \mathrm{~nm}$ increments and the effect on performance parameters is shown in Fig. (3). The device's performance is excellent at $850 \mathrm{~nm}$, and it achieves the maximum efficiency. At $850 \mathrm{~nm}$, the device's performance is excellent, with the maximum efficiency of $24.22 \%$ achieved by using Voc $6.20 \mathrm{~V}$, Jsc 30.77 $\mathrm{mA} / \mathrm{cm} 2$, and $\mathrm{FF} 12.68 \%$.

\subsubsection{Thickness optimized on Electron Transport Layer}

Figure 4 illustrates the effect of ETL thickness and performance on ab-layer at $850 \mathrm{~nm}$. When the ETL thickness is $20 \mathrm{~nm}$, we get the best performance on the simulated device with the highest PCE of $24 \%$, which is increased by $0.02 \%$ efficiency with FF of $12.68 \%$, Voc of $6.20 \mathrm{~V}$, and Jsc of $30.77 \mathrm{~mA} / \mathrm{cm} 2$.

\subsubsection{Thickness optimized in Hole Transport layer}

From Fig. 5. Shows the impact on the HTL and the device performance at $850 \mathrm{~nm}$ Ab-layer. When the thickness of the Ab-layer is at $850 \mathrm{~nm}$, we reach the maximum PCE $24.22 \%$ at $10 \mathrm{~nm}$ thickness of HTL with FF of $12.68 \%$, Voc of $6.20 \mathrm{~V}$, Jsc of $30.77 \mathrm{~mA} / \mathrm{cm}^{2}$.

\subsubsection{Effect of $\mathrm{Nt}$ of the optimized device}


In this simulation, the Nt of ab layered varied between $10^{12} \mathrm{~cm}^{-3}$ and $10^{18} \mathrm{~cm}^{-3}$ to find the best absorber thickness to find the variation in PCE, as shown in the Fig. 6,7,8 for the simulated device. PCE at other parameters of the simulated solar cell decreased as the absorber layer's Nt increased. As the defect density decreased, the efficiency stabilized at a certain point in this work, with the device performing well at $10^{16} \mathrm{~cm}^{3}(\mathrm{Nt})$ of absorber layer. The device performs best at $10^{18} \mathrm{~cm}^{-3}$ and $10^{20} \mathrm{~cm}^{-3}$ for ETL and HTL, respectively.

\subsubsection{Effect of Bandgap in the simulation device}

Sn-based PSC has a tunable band gap ranging from 1.3eV to $2.15 \mathrm{eV}$. (vedanayakam, mandadapu.,2017). In this simulation, the bandgap of the optimized solar cell ranged from $1.2 \mathrm{eV}$ to $2.0 \mathrm{eV}$ for the best ablayer to determine the variation in efficiency and other parameters. As shown in the figure 9 , as the bandgap increased, PCE, FF, and Jsc decreased slightly while Voc increased. Jsc decreased as the bandgap increased, owing to less electron generation. After several simulations, the device was tested at $1.4 \mathrm{eV}$. Similarly, we optimised the bandgap of ETL and HTL until we found the best performance of Cul at $2.8 \mathrm{eV}$ and $\mathrm{ZnOS}$ at $2.4 \mathrm{eV}$ after several attempts. Figure 10 depicts the external quantum efficiency curve for the device's best absorber layer.

\section{Conclusion}

1D SCAPS was used in this study to investigate the optimized and simulated behaviors of the Sn-based PSC with ETL as ZnOS and HTL as Cul configuration. The working temperature $340 \mathrm{k}$ for this simulation study at standard illumination of Air mass at 1.5G, the perovskite layer from150 nm to $1050 \mathrm{~nm}$ and the optimum layer range for HTL and ETL as $10-50 \mathrm{~nm}$ respectively both layers. The best layer thickness ranges from ZnOS are $20 \mathrm{~nm}$ and $\mathrm{Cul}$ is $10 \mathrm{~nm}$ respectively. The best defect density is performed at $10^{16} \mathrm{~cm}^{-3}$ for this simulated device. The band gap of ab-layer HTL, ETL were to change from after several simulation $1.4 \mathrm{eV}, 2.4 \mathrm{eV}, 2.8 \mathrm{eV}$, respectively. The device performed well and good at when $\mathrm{Nt}$ of the ablayer $10^{16} \mathrm{~cm}^{-3}$ with bandgap $1.4 \mathrm{eV}$. When the optimized input parameter values are considered, the highest efficiency achieved is $24.22 \%$ (FF of $12.68 \%$, Voc of $6.20 \mathrm{~V}$, Jsc of $30.77 \mathrm{~mA} / \mathrm{cm}^{2}$ ). When we use Cul as the hole transport layer and ZnOS as the electron transport layer in a FASnl 3 -based solar cell, we get the best results, and Cul and ZnOS are the best replacements for Spiro-OMeTAD and $\mathrm{TiO}_{2}$. The simulated result stands for only replacement materials for $\mathrm{FAPbl}_{3}$, Spiro-OMeTAD and $\mathrm{TiO}_{2}$ because $\mathrm{Pb}$ based material had high toxicity for that reason we use $\mathrm{Sn}$ based ab-layer in this work. Spiro-OMeTAD and $\mathrm{TiO}_{2}$ are too costly for that reason in this work we used lost cost Cul, ZnOS as HTL and ETL respectively.

\section{Abbreviations}

PSC- Perovskite solar cell 
PV-Photovoltaic technology

SCAPS- Solar cell Capacitance simulation

$\mathrm{FASnl}_{3}$ - Formamidinium tin iodide

$\mathrm{MASnl}_{3}$ - Methylammonium tin iodide

ZnOS- Zinc oxysulphide

FA- Formamidinium

Cs- Cesium

MA- Methylammonium

Sn- Tin

Pb-Lead

Cu- Copper

Copper iodide- Cul

ETL- Electron transport layer

HTL- Hole transport layer

$\mathrm{TiO}_{2}$-Titanium Oxide

Spiro-OMeTAD - 2,2',7,7'-Tetrakis[N,N-di(4-methoxyphenyl)amino]-9

Voc- Voltage output circuit (Voc),

Jsc- Current density

FF- Fill factor

PCE- Power conversion Efficiency

$\mathrm{N}_{\mathrm{t}^{-}}$- Donor

$\mathrm{N}_{\mathrm{A}^{-}}$- Acceptor

\section{References}


1. P.Touni, S.O. Oseni, G.Sharma, Q.Yan, G.T.Mola, Perovskite photovoltaic solar cell: an overview of current status, Renew.Sustain.Energy Rev.91 (2018) 1025-1044, http://doi.org/10.1016/j.rser.2018.04.069.

2. L.Serrano-Lujan, N.Espinosa, T.T.Lasrsen-Olsen, J.Abad, A.Urbina, F.C.Krebs, Tin-and based perovskite solar cell under scrutiny: an environmental perspective, Adv.Energy Matter,5 (20) (2015), 1501119.

3. G.Xing, N. Mathews, S.Sun, S.S.Lim, Y.M.Lam et.al., Long-range balanced electron- and hole transport lengths in organic-inorganic CH3NH3PbI3.Science 342 (6156), 344-347 (2013). https://doi.org/10.1126/science.1243167.

4. S.D.Stranks, G.E.Eperon, G.Eperon,G.Grancini, C.menelaou, M.J.P. Alcocer et al., Electron-Hole diffusion length exceedimg 1 micrometer in an organometal trihalide perovskite absorber. Science 342 (6156), 341-344 (2013). http://doi.org/10.1126/science.1243982.

5. P.Docampo, J.M.Ball, M.Darwich, G.E. Eperon,H.J.Snaith, Efficient organometal trihalide perovskite planar heterojunction solar cells on flexiable polymer substrates. Nat.Commun. 4,27612766(2013).https://doi.org/10.1038/ncomms3761.

6. G.Schileo, G.Grancini, Lead or no lead Availability, toxicity, sustainability and environmental impact of lead free perovskite solar cell, J.Mater.Chem. C9(2021) 67-76, https://doi.org/10.1039/DOTC04552G.

7. M.Konstantakou, T.Stergiapolou, A critical review on tin halide perovskite solar cells, J. Mater. Chem.5 (2017) 11518-11549, https://doi.org/10.1039/C7TA00929A.

8. W.Zhou, Y.Zhou, X.Zhou. R. Fu, Q.Li, Y.Zhao, K. Liu, D.Yu.Q.Zhao, J.phys.chem.Lett.8(2017).41224128.

9. M.A.Green, E.D.Dunlop, J.Hohlebinger, M.Yoshita, N.Kopidakis, A.Hobaillie, Prog. Photovolt.28 (2020) 3-15.

10. Minghao Wang, W.Wang, B.Ma, A.Shen, L.Liu, K.Cao, S.Chen, W.huang. Lead Free Perovskite Materials for Soalr Cells.Nano-Micro Lett. (2021).hhtps://doi.org/10.1007/s40820-020-00578-z.

11. A.G.Kontos, A.kaltzoglou, E.Siranidi,D.Palles, G.K.Angeli, M.K.Arfanis,et.al,. Structural stability, vibrational propertyes and photoluminescence in CsSnl3 perovskite upon the addition of SnF2, Inorg. Chem.56 (1) (2017) 84-91.

12. S.Abdelaziz, A.Zekry, A. Shaker, M.Abouelatta Investigating the performance of fomamidinium tin based perovskite solar cell by SCAPS device simulation.https://doi.org./10.1016/j.optmat.2020.109738.

13. R.L. Milot,G.E.Eperon, T.Green, H.J.Snaith radiative monomolecular recombination boosts amplified spontaneous emission in HC (NH2)2SnI3 perovskite films, J.Phys.chem.lett.7 (20) (2016) 41784184,https://doi.org/10.1021/acs.jpclett.6b02030.

14. T.M.Koh, T.Krishnamoorty, N.Yantara, C.Shi. W.L.Leong. Formamidinium tin-based perovskite with Iow Eg for photovoltaic application, J.mater.chem.A3 (29) (2015) 14996-15000, https://doi.org/10.1039/C5TA00190K. 
15. Y.Zhao, K.Zhu. Organic-inorganic hybrid lead perovskite for optoelectronic and electronic applications. Chem, Soc. Rev.45(3), 655-689 (2016). https;//doi.org/10.1039c4cs00458b.

16. Xin Li, Junyou Yang,Qinghui Jiang, Synergistic effect to high performance perovskite solar cell with reduced hysreresis and improved stability by the introduction of $\mathrm{Na}$ treated $\mathrm{TiO} 2$ and spraying deposited Cul as transport layers, ACS Appl.Mater. Interfaces 9 (47) (2017) 41354-41362.

17. Mostafa M. salah. Kamel M.Hassan, Mohamed Abouelatta, Ahmed shaker, A comparative stuy of different ETM's in perovskite solar cell with inorganic copper iodide as HTM, hhtps;//doi./org/10.1016.j.ijleo.2018.10.052.

18. S.Bansal, P.Aryal, evaluation of new materials for electron and hole transport layer in perovskite based solar cell through SCAPS-1D simulations, in;IEEE $43^{\text {rd }}$ photovoltaic Specialists conference (PVSC), 2016,https;//doi.org/10.1109/PVSC.2016.7749702,0747-0750.

19. Mandadapu U, Victor Vedanayakam S, Thyagarajan K (2017) Numerical simulation of CH3NH3PbI3xClx perovskite solar cell using SCAPS-1D. Int J Eng Sci Invention 2:40-45

20. Mare Burgelman, Koen Decock, Samira Khelifi., Aimi Abass,Advanced electrical stimulation of thin film solar cell, Thin solid film, 535 (2013) 296-301.

21. Hechavarría-Difura , F.J. Sánchez-Rodríguezb , Maykel Courelc , Hailin Hu Optimization of CH3NH3Pbl3 perovskite solar cells: A theoretical and experimental study. Solar Energy 199 (2020) 198-205.

22. M. I. Hossain, F. H. Alharbi, and N. Tabet, "Copper oxide as inorganic hole transport material for lead halide perovskite-based solar cells," Sol. Energy 120, 370-380 (2015).

23. K.Deepthi Jayan, Varkey Sebastian.Comprehensive device modeling and performance analysis of MASnl3 based perovskite solar cell with diverse ETL, HTL, and back metal contacts, Solar cell, 2021.

24. Y. Ogomi, A. Morita, S. Tsukamoto, T. Saitho, N. Fujikawa, Q. Shen, et al., CH3NH3SnxPb(1-x)I3 perovskite solar cells covering up to 1060 nm, J. Phys. Chem. Lett. 5 (6) (2014) 1004-1011.

25. Zhao P, Liu Z, Lin Z, Chen D, Jie S, Zhang C, Zhang J, Chang J, Hao Y (2018) Device simulation of inverted $\mathrm{CH} 3 \mathrm{NH} 3 \mathrm{Pbl} 3-\mathrm{xClx}$ perovskite solar cells based on $\mathrm{PCBM}$ electron transport layer and $\mathrm{NiO}$ hole transport layer. Sol Energy 169:11-18

\section{Tables}

Table.1 $[3,10,15,20,21,22]$ 


\begin{tabular}{|c|c|c|c|}
\hline Material property & ZnOS & $\mathrm{FASnl}_{3}$ & Cul \\
\hline Thickness ' $\mathrm{t}$ '(nm) & Varied & Varied & Varied \\
\hline Bandgap ‘Eg' (eV) & 2.8 & 1.4 & 2.6 \\
\hline Electron affınity ' $\chi$ ' (eV) & 3.9 & 3.52 & 3.9 \\
\hline Relative Dielectric permittivity ' $\varepsilon_{r}$ ' & 3 & 8.2 & 4 \\
\hline CB effectivite density of state ${ }^{\prime} N_{c}{ }^{\prime}\left(\mathrm{cm}^{-3}\right)$ & $1 \mathrm{E}+20$ & $1.0 \mathrm{E}+18$ & $1 \mathrm{E}+21$ \\
\hline VB effective density of state ' $\mathrm{N}_{\mathrm{c}}{ }^{\prime}\left(\mathrm{cm}^{-3}\right)$ & $1 \mathrm{E}+20$ & $1.0 \mathrm{E}+18$ & $2 \mathrm{E}+20$ \\
\hline Electron mobility ' $\mu_{n}$ ' ( $\left.\mathrm{cm}^{2} / \mathrm{V} . \mathrm{s}\right)$ & $1 \mathrm{E}-4$ & 22 & 0.01 \\
\hline Hole mobility ' $\mu_{\mathrm{p}}$ ' ( $\left.\mathrm{cm}^{2} / \mathrm{V} . \mathrm{s}\right)$ & $1 \mathrm{E}-4$ & 22 & 0.01 \\
\hline Donor concentration ' $\mathrm{N}_{\mathrm{D}}{ }^{\prime}\left(\mathrm{cm}^{-3}\right)$ & $1 \mathrm{E}+7$ & 0 & $1 \mathrm{E}+20$ \\
\hline Acceptor concentration ' $\mathrm{N}_{\mathrm{A}}$ ' $\left(\mathrm{cm}^{-3}\right)$ & $1 \mathrm{E}+7$ & 7.0E+16 & - \\
\hline Defect density ' $\mathrm{Nt}^{\prime}\left(\mathrm{cm}^{-3}\right)$ & - & $2.0 \mathrm{E}+15$ & - \\
\hline
\end{tabular}

Table.2: Parameters for back and front contact. $[23,24,25]$

\begin{tabular}{|lll|}
\hline Parameters & Back contact & Front contact \\
\hline Surface recombination velocity of electrons $(\mathrm{cm} / \mathrm{s})$ & $1.00 \mathrm{E}+7$ & $1.000 \mathrm{E}+5$ \\
\hline Surface recombination velocity of holes $(\mathrm{cm} / \mathrm{s})$ & $1.000 \mathrm{E}+5$ & $1.000 \mathrm{E}+7$ \\
\hline Metal work function $(\mathrm{eV})$ & 5.144 & 4.43 \\
\hline Majority carrier barrier height relative to $\mathrm{Ef}(\mathrm{eV})$ & -0.0444 & -0.0600 \\
\hline Majority carrier barrier height relative to $\mathrm{Ev}(\mathrm{eV})$ & -0.0000 & -0.0028 \\
\hline
\end{tabular}

\section{Figures}




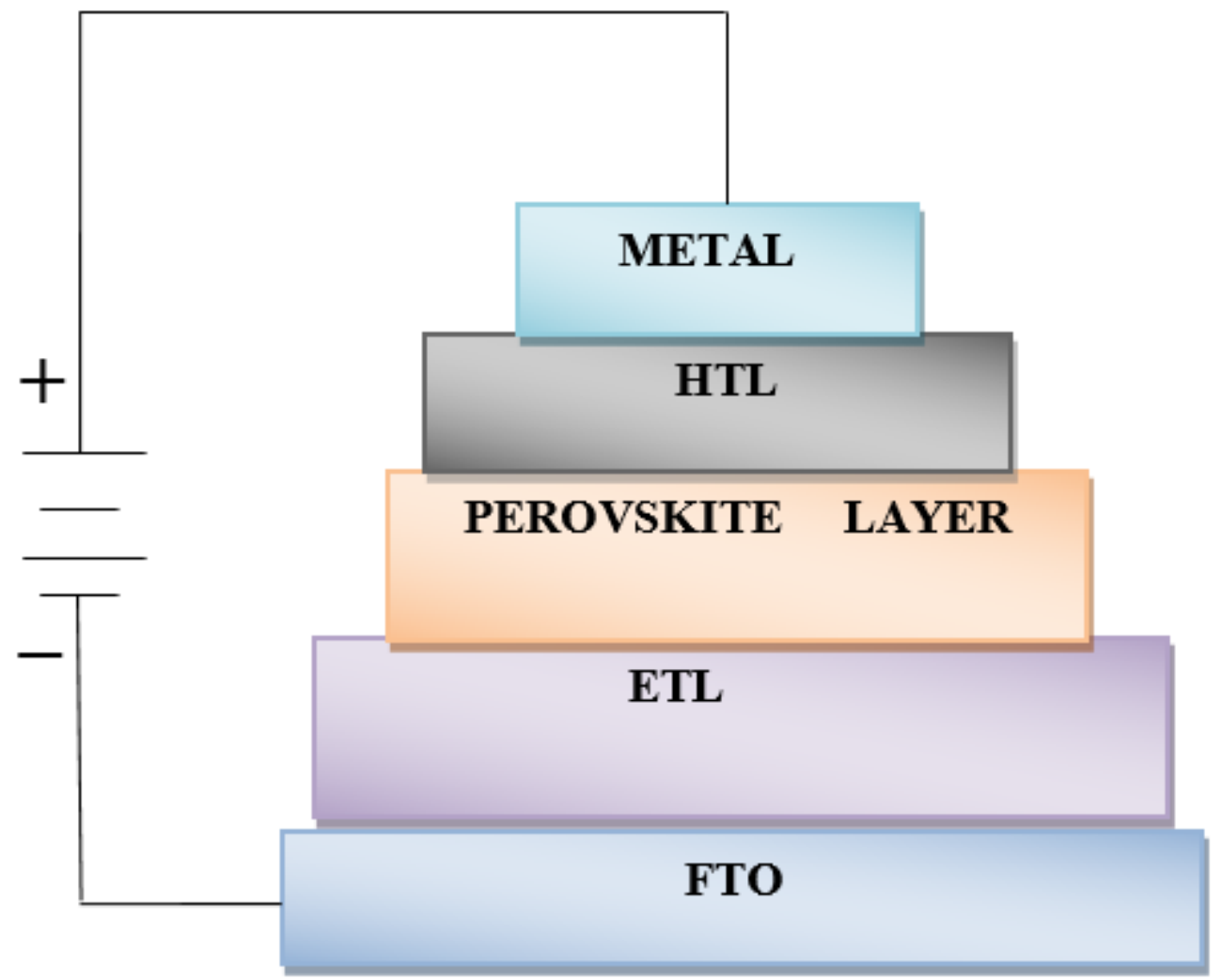

Figure 1

(a). Cell configuration of $\mathrm{FASnl}_{3}$ designed solar cell 

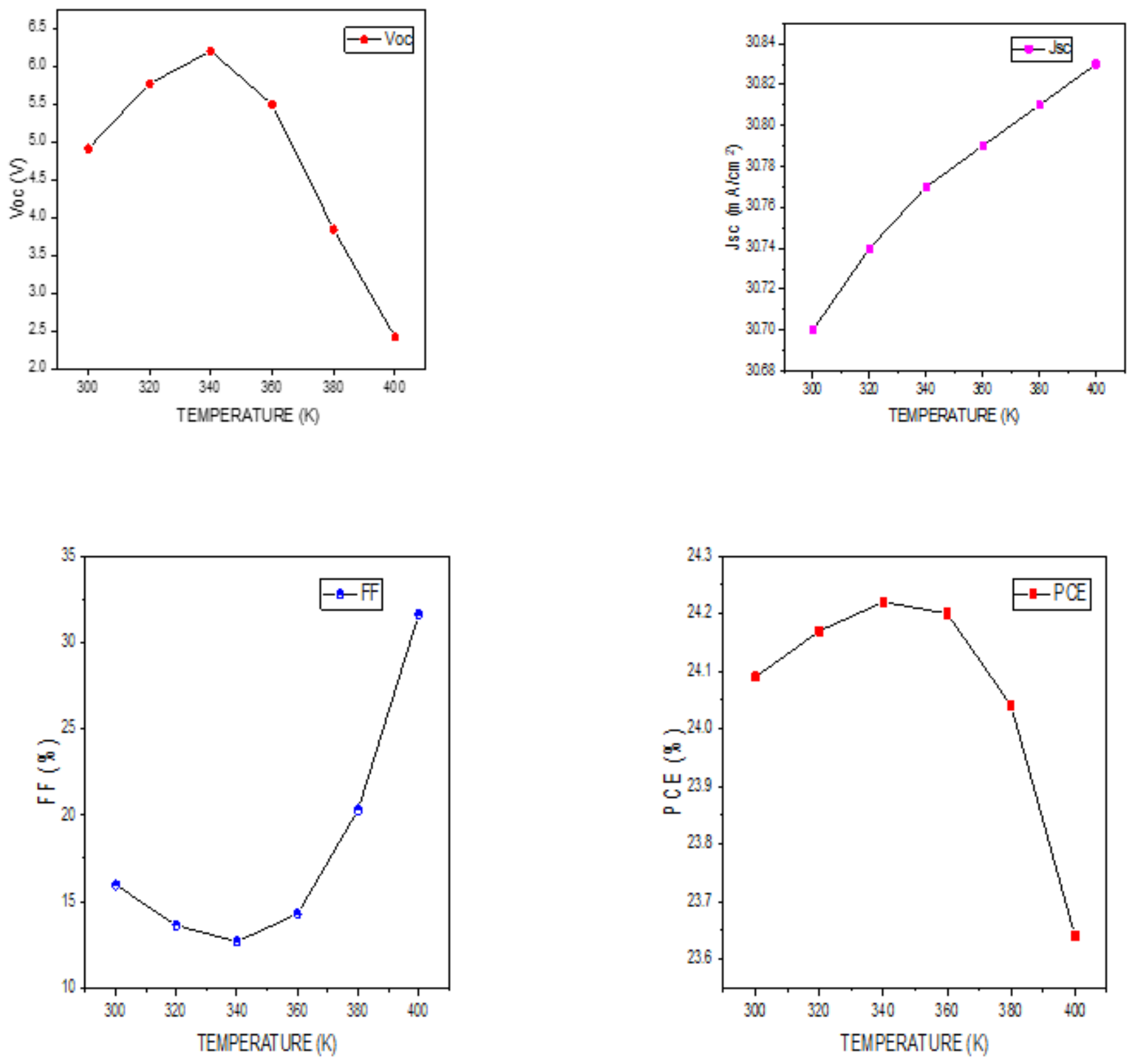

Figure 2

Temperature VS Voc, Jsc, FF, PCE 

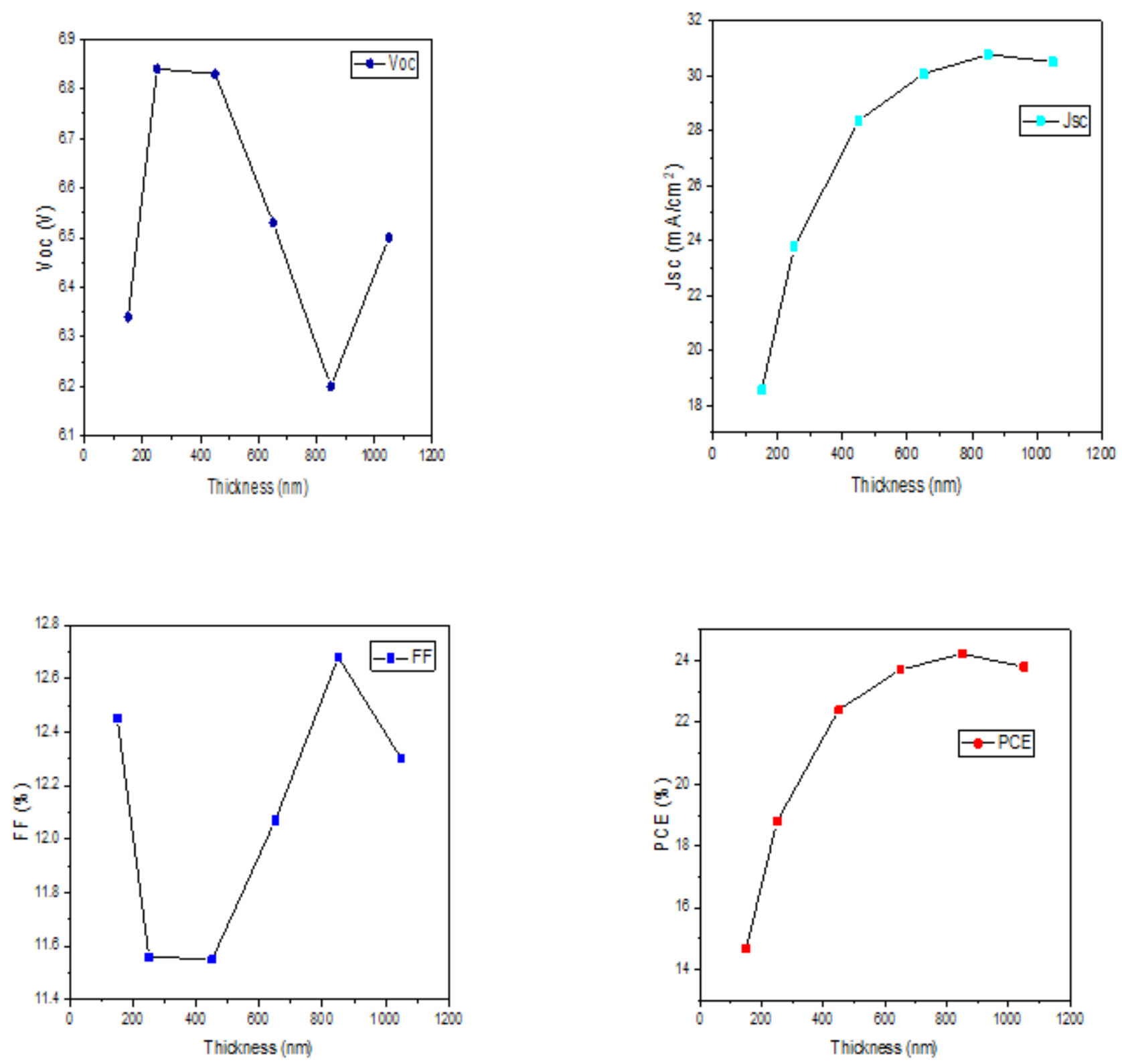

Figure 3

Thickness of active layer Vs Voc, Jsc, FF, P 

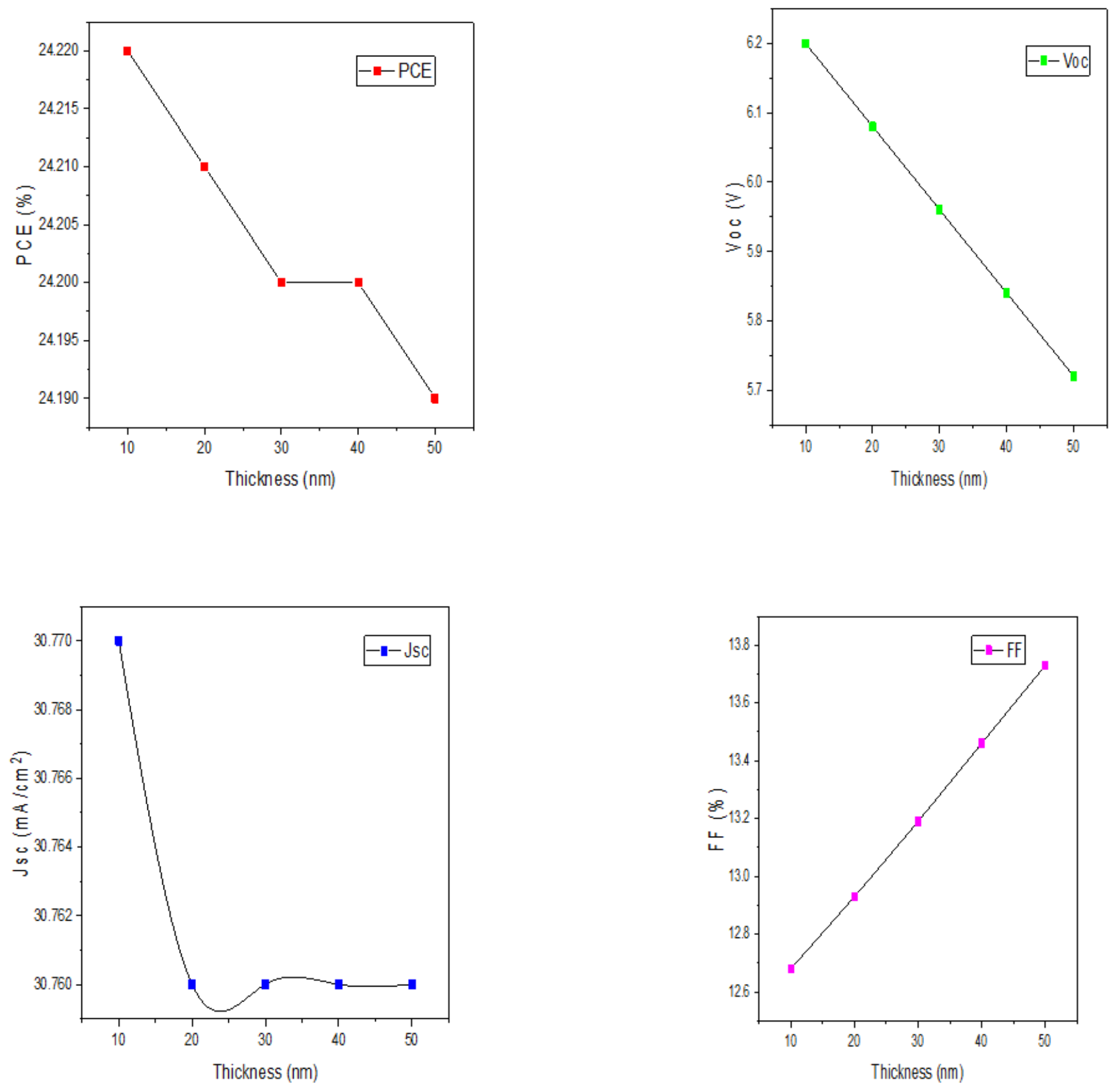

Figure 4

Thickness of Cul Vs Voc, Jsc, FF, PCE 

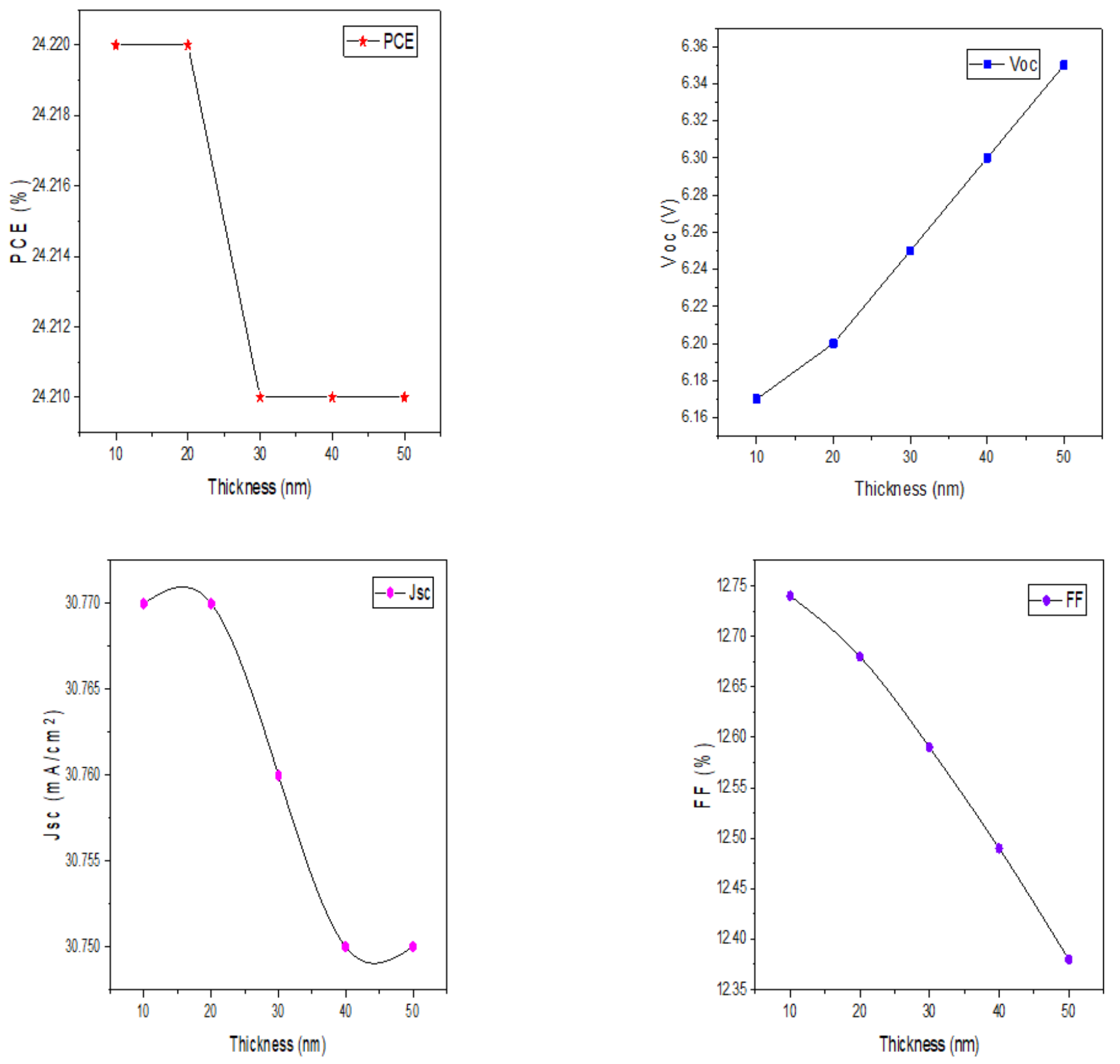

Figure 5

Thickness of ZnOS Vs Voc, Jsc, FF, PCE 


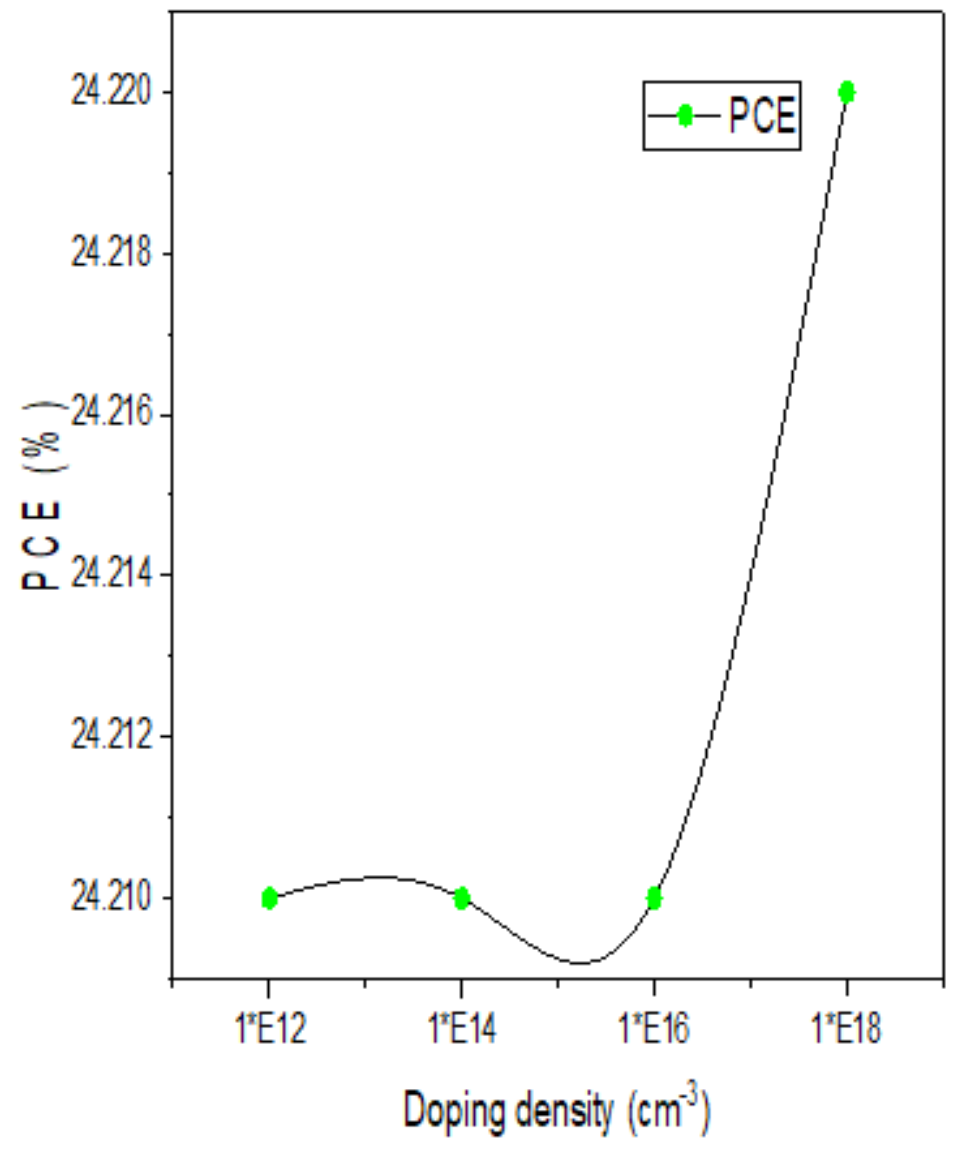

Figure 6

HTL Vs Doping density 


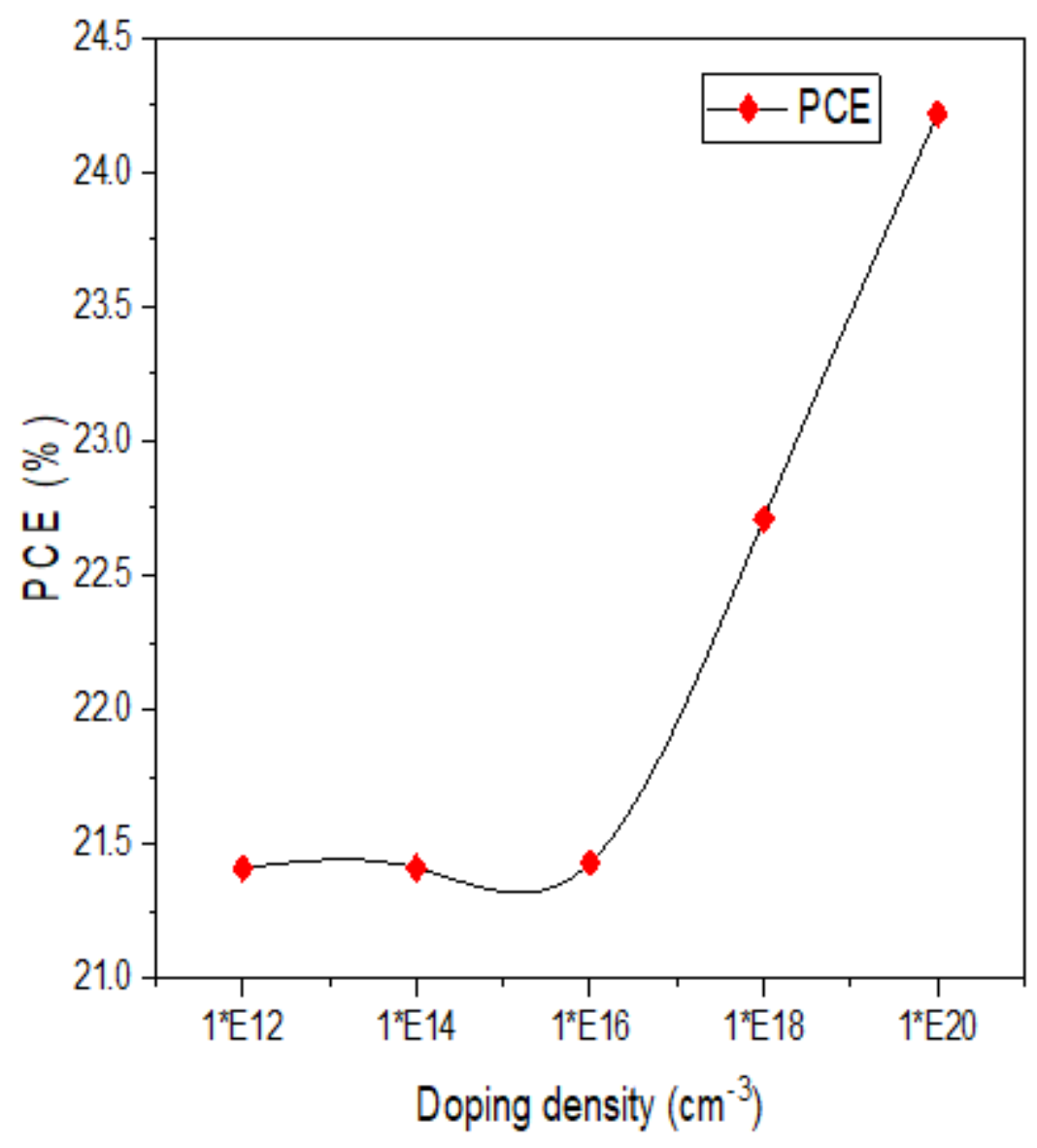

Figure 7

ETL Vs Doping density 


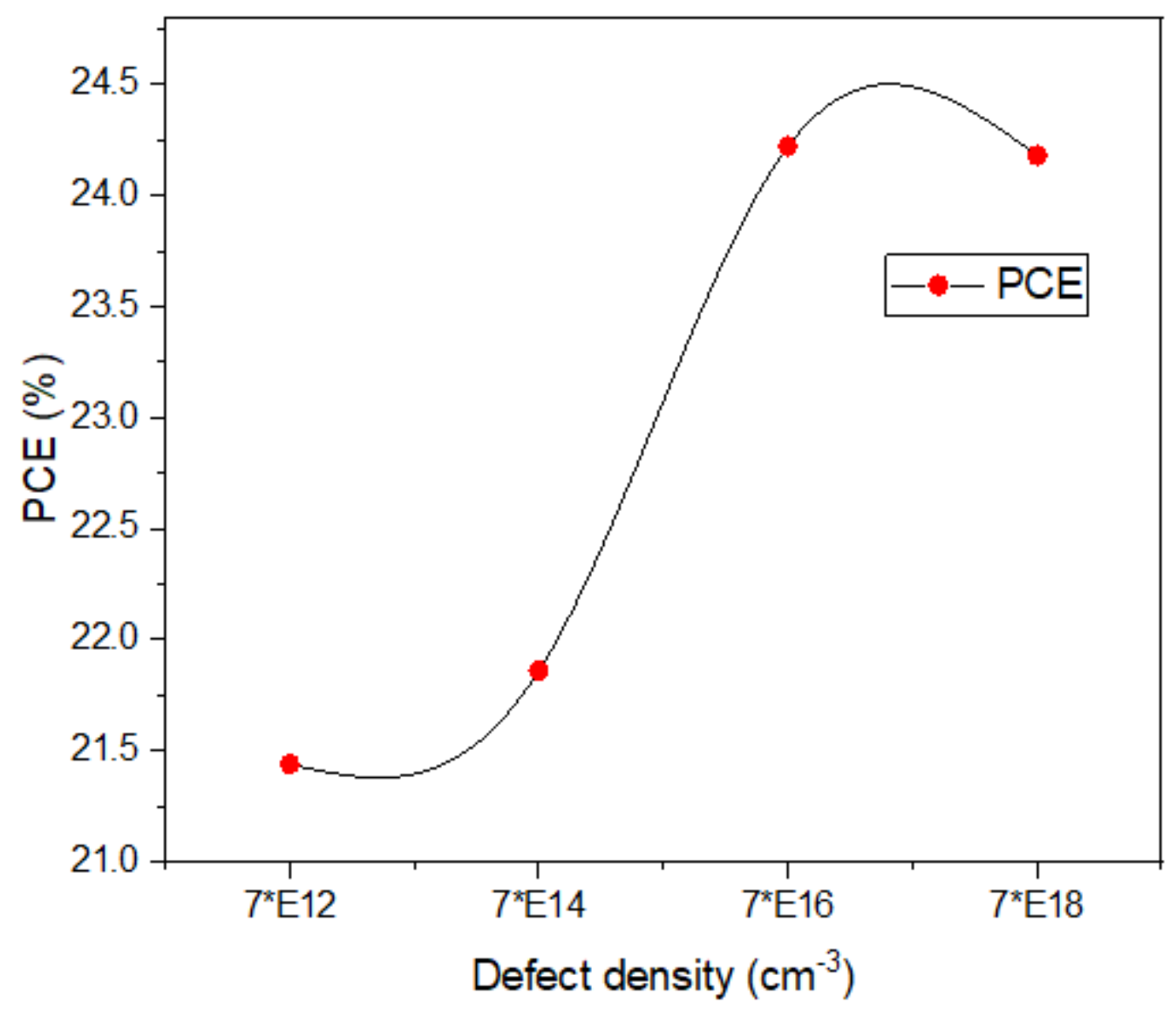

Figure 8

Defect density Vs PCE 

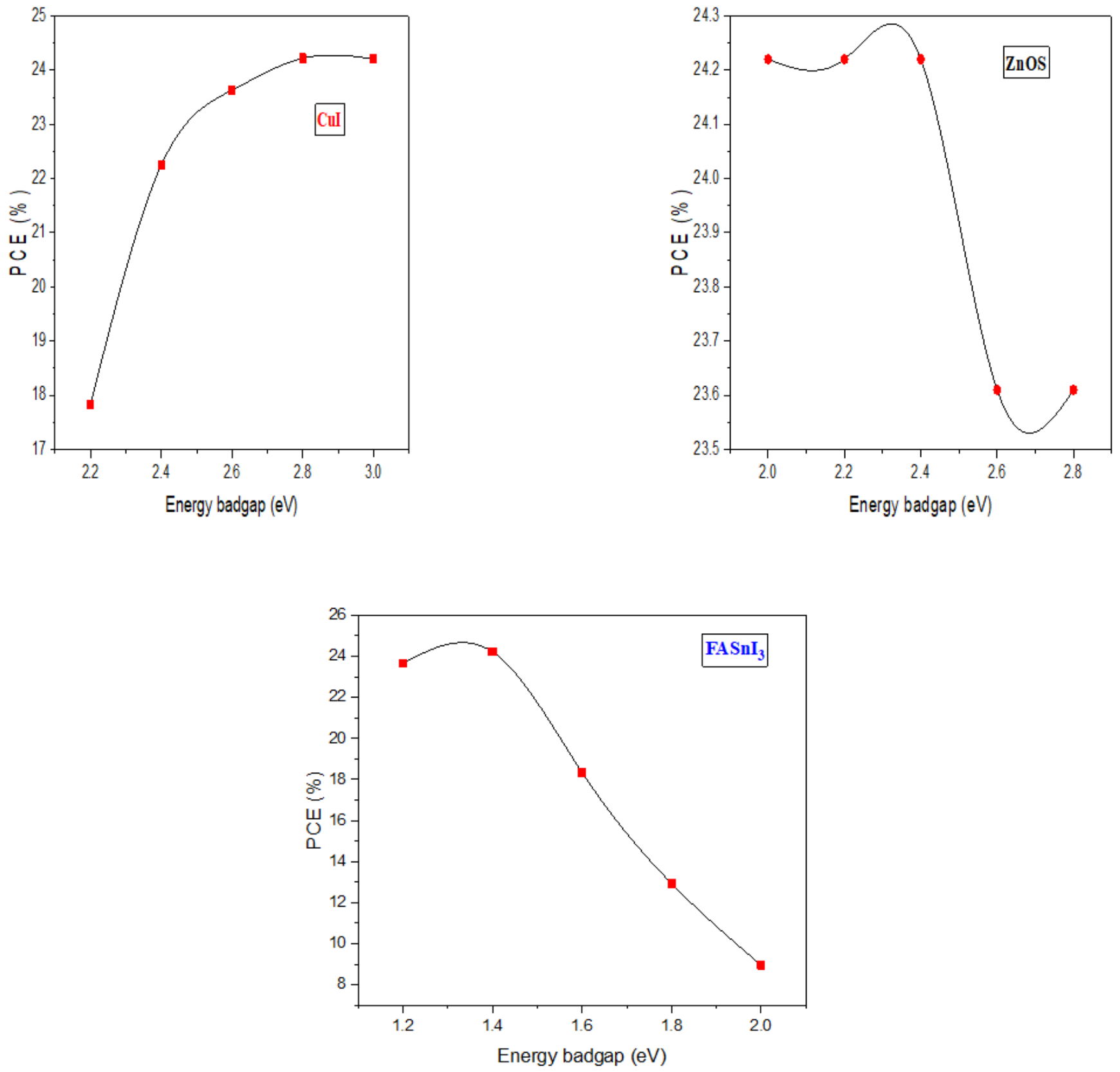

Figure 9

Bandgap for best perovskite layer, HTL and ETL 


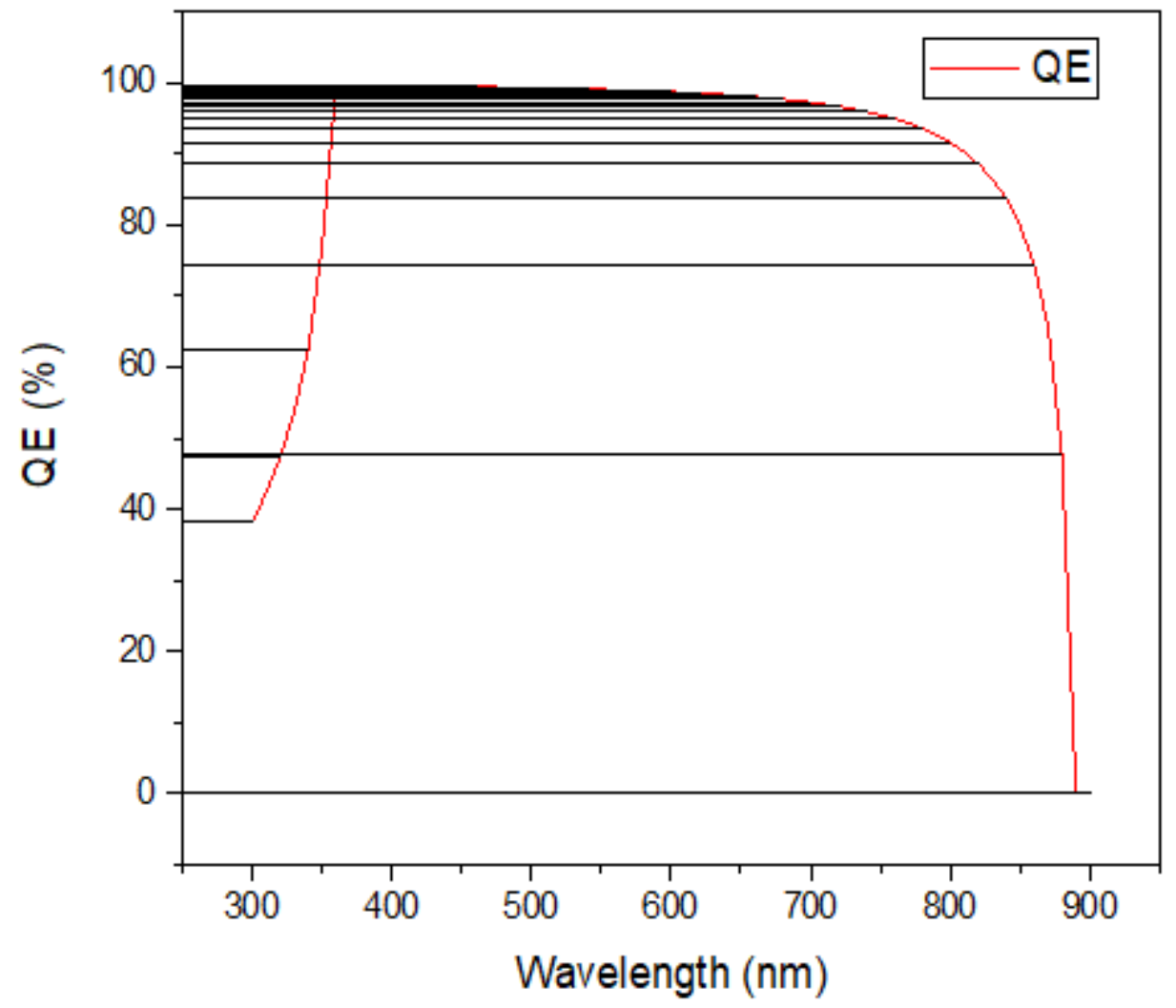

Figure 10

QE vs Wavelength 